\title{
Neoliberalismo e a reprodução de práticas discursivas anti- cotas nos grupos historicamente discriminados: uma análise crítica.
}

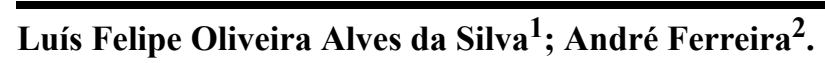

1 - Instituto Federal do Rio de Janeiro - Campus Pinheiral. Assistente em Administração. Mestrado em Administração pelo PPGA/UFF, Brasil (em andamento). e-mail: luisalves@id.uff.br

2 - Universidade Federal Fluminense. Departamento de Administração e Administração Pública. Programa de Pós-Graduação em Administração (PPGA/UFF). Vice-Coordenador PPGA/ UFF Professor Associado. Doutorado em Políticas Públicas pelo IE/PPED - UFRJ, Brasil. e-mail: andref@id.uff.br. ORCID: http://orcid.org/0000-0002-1430-4537

\section{Resumo}

Este trabalho relaciona o neoliberalismo, especificamente o conceito de neoliberalismo de baixo para cima desenvolvido por Gago (2018), às críticas ao sistema de cotas brasileiro direcionadas por indivíduos pertencentes a minorias étnicas e raciais, reforçando o enraizamento de ideias neoliberais nas camadas mais populares da sociedade. A possível atuação dos Think Tanks da direita brasileira pode justificar a padronização discursiva dos formadores de opinião, contribuindo para o enraizamento de tais ideias neoliberais. No Brasil, formadores de opinião oriundos de grupos marginalizados reforçam este conceito ao adotarem práticas discursivas neoliberais, como menor intervenção estatal e ao se posicionarem contra o sistema de cotas, defendendo a meritocracia. O sistema de cotas enfrenta críticas dentro da própria universidade, também associadas à ideia de meritocracia. Desconstruindo tais argumentações, os conceitos de Estado mínimo e de livre mercado esbarram no fato de o ideal de mercado perfeitamente concorrencial estar longe da realidade, enfraquecendo a mão invisível do mercado. A questão meritocrática não é rechaçada pelas cotas, pois a concorrência por vagas permanece, embora sob um novo contexto. Considerando estudos que mostram o aumento da população negra nas universidades, o sistema de cotas cumpre o que se propõe a fazer: democratizar o acesso ao ensino superior.

Palavras-chave: Neoliberalismo; Sistema de cotas; Think Tanks. 


\title{
Neoliberalism and the reproduction of anti-quota discursive practices in historically discriminated groups: a critical analysis.
}

\begin{abstract}
This paper links neoliberalism, specifically the bottom-up concept of neoliberalism developed by Gago (2018), to the criticisms of the Brazilian quota system directed by individuals belonging to ethnic and racial minorities, reinforcing the rooting of neoliberal ideas in the most popular layers of the society. The possible action of the Think Tanks of the Brazilian right may justify the discursive standardization of opinion makers, contributing to the rooting of such neoliberal ideas. In Brazil, opinion formers from marginalized groups reinforce this concept by adopting neoliberal discursive practices, such as less state intervention and taking a stand against the quota system, defending meritocracy. The quota system faces criticism within the university itself, also associated with the idea of meritocracy. Deconstructing such arguments, the concepts of minimum state and free market run into the fact that the ideal of a perfectly competitive market is far from reality, weakening the invisible hand of the market. The meritocratic issue is not rejected by quotas, as competition for vacancies remains, although in a new context. Considering studies that show an increase in the black population in universities, the quota system fulfills what it proposes to do: democratize access to higher education.
\end{abstract}

Keywords: Neoliberalism; Quota system; Think Tanks. 


\section{INTRODUÇÃO}

A crise de governabilidade enfrentada pelo liberalismo, em meados da década de 1970, propiciou o surgimento do neoliberalismo, que representou uma resposta a esta crise, como forma de superar as dificuldades do capitalismo e dos conflitos sociais (DARDOT; LAVAL, 2016).

As características do sujeito neoliberal são definidas como o sujeito que governa a si mesmo e é instrumento de seu próprio sucesso profissional e social, e podem ser encontradas nos discursos dos formadores de opinião da direita brasileira.

Um dos exemplos é o discurso de um dos líderes do Movimento Brasil Livre, Fernando Holiday, vereador eleito pela cidade de São Paulo, na esteira do movimento Bolsonarista. Apesar de negro, pobre e homossexual, afirma que as cotas raciais acabam por reforçar o racismo (MESSENBERG, 2017).

Neste contexto, este trabalho relaciona o neoliberalismo de baixo para cima, exposto por Gago (2018), às críticas ao sistema de cotas brasileiro direcionadas por indivíduos pertencentes a minorias étnicas e raciais, reforçando o enraizamento de ideias neoliberais nas camadas mais populares da sociedade.

Para isto, o presente trabalho aborda o sistema de cotas, a origem das políticas de ação afirmativa nos Estados Unidos da América, sua finalidade e sua aplicação do Brasil. Expõe a crise do liberalismo e o surgimento do neoliberalismo, que surge como resposta a uma crise do modo de governo liberal. Também é apresentado o conceito de neoliberalismo de baixo para cima de Gago (2018), relacionando-o com o enraizamento de ideias neoliberais no contexto universitário e o discurso contrário ao sistema de cotas de indivíduos pertencentes a minorias étnicas e raciais. Por fim, são apresentadas as considerações finais, considerando os objetivos do sistema de cotas e os resultados já alcançados desde sua implantação. 


\title{
2. O SISTEMA DE COTAS
}

O sistema de cotas é um tipo de política pública de ação afirmativa, tal como os programas de bolsa permanência e outras políticas públicas (ABREU; LIMA, 2018). De acordo com Oliven (2007), as ações afirmativas buscam proteger minorias e grupos que tenham sido discriminados no passado em uma determinada sociedade.

\begin{abstract}
A ação afirmativa visa remover barreiras, formais e informais, que impeçam o acesso de certos grupos ao mercado de trabalho, universidades e posições de liderança. Em termos práticos, as ações afirmativas incentivam as organizações a agir positivamente a fim de favorecer pessoas de segmentos sociais discriminados a terem oportunidade de ascender a postos de comando (OLIVEN, 2007, p. 30).
\end{abstract}

De acordo com Souza e Secchi (2015), políticas públicas são diretrizes elaboradas para o enfrentamento de um problema público. Considerando esta definição, o sistema de cotas enquadra-se como uma política pública, uma vez que busca enfrentar um problema público - a sub-representação de classes menos favorecidas à educação superior.

O sistema de cotas é um tema bastante controverso, com correntes que defendem o sistema como reparação histórica e correntes que criticam a política por diversas razões (ALMEIDA; RODRIGUES, 2019). Segundo os autores, uma das razões apontadas pela corrente crítica a política é a existência de um possível gap existente na formação escolar por parte dos beneficiados, gerando perda qualitativa de capital humano na universidade. O próprio trabalho de Almeida e Rodrigues (2019) contesta a existência desse gap. Por meio da metodologia do matching, comparando o desempenho escolar e o número de reprovações entre os estudantes beneficiados ou não pela Lei de Cotas nos anos 2013, 2014 e 2015 na Universidade Federal de Viçosa, os autores observaram que não existe diferença significativa de desempenho acadêmico e número de reprovações entre cotistas e não cotistas. 
Tal constatação reforça a argumentação de Durham (2005), que admite existir grande lacuna educacional entre estudantes brancos e negros. Entretanto, tal lacuna caracteriza-se muito mais pela subrepresentação histórica da população negra na universidade do que pela diferença de conhecimento entre cotistas e não cotistas (DURHAM, 2005).

Estudo semelhante ao de Almeida e Rodrigues (2019) foi realizado por Wainer e Melguizo (2018), o qual comparou o desempenho de alunos cotistas e não-cotistas no Exame Nacional de Desempenho de Estudantes (ENADE) de 2012 a 2014. Os resultados não apresentaram diferenças práticas entre o conhecimento destes grupos distintos (WAINER; MELGUIZO, 2018).

O Programa de Ação Afirmativa e Inclusão Social (PAAIS) da Universidade Estadual de Campinas (UNICAMP) é outro exemplo, como apontam Andrade et al. (2012). Os autores argumentam que os estudos anteriores à implantação do PAAIS mostraram que alunos da Unicamp oriundos do ensino público apresentavam rendimento semelhante ou superior aos alunos oriundos do ensino privado aprovados com notas similares no vestibular. Dados mais atuais apontam menor índice de abandono de curso e melhor rendimento acadêmico por parte dos ingressantes da Unicamp pelo PAAIS do que os admitidos pela modalidade clássica de vestibular (ANDRADE et al., 2012).

Para Contins e Sant'ana (1996), o estudo das ações afirmativas remete de forma axiomática aos Estados Unidos da América (EUA), país onde o termo se originou e que contém um importante arcabouço jurídico acerca do tema. Considerando o exposto pelos autores, a presente seção será dividida em duas subseções, tratando o sistema de cotas nos Estados Unidos da América e no Brasil.

\subsection{O sistema de cotas nos Estados Unidos da América}

O surgimento do sistema de cotas brasileiro se assemelha ao norte-americano (OLIVEN, 2007), justificando uma breve contextualização do sistema de cotas norte-americano. 
Nos anos 60, os norte-americanos viviam um momento de reivindicações democráticas internas, expressas principalmente no movimento pelos direitos civis, cuja bandeira central era a extensão da igualdade de oportunidades a todos. [...] É nesse contexto que se desenvolve a ideia de uma ação afirmativa, exigindo que o Estado, para além de garantir leis anti-segregacionistas, viesse também a assumir uma postura ativa para a melhoria das condições da população negra (MOEHLECKE, 2002, p. 198).

A busca pela melhoria das condições da população negra, exposta por Moehlecke (2002), tem sua justificativa na própria constituição americana, promulgada em 1787, a qual apresentava provisões que facilitavam a continuação da escravidão (FERES JÚNIOR, 2007). Mesmo após a aprovação da décima terceira emenda constitucional, a qual aboliu a escravidão em todo o território americano (FERES JÚNIOR, 2007), os negros não eram necessariamente livres (OPIE; ROBERTS, 2017). A segregação localizada continuava nos estados do sul, nas forças armadas e no mercado de trabalho (PERIA, 2004). A filosofia do igual, mas separado representou uma barreira, negando aos negros o livre acesso à moradia, serviços públicos e restaurantes (BAYMA, 2012).

Tais distorções culminaram, durante a primeira metade do século XX, em inúmeros enfrentamentos nos principais centros urbanos, polarizando a sociedade americana em dois grupos: os segregacionistas e os favoráveis à integração social (OLIVEN, 2007). Segundo a autora, a polarização da sociedade americana e os conflitos da primeira metade do século XX sucederam um novo Civil Rights Act, aprovado pelo Congresso americano em 1964, que concedeu ao governo federal poderes para implementar a dessegregação e banir todo tipo de discriminação. Segundo Peria (2004), a Lei alargou e fortaleceu a aplicação do princípio da ação afirmativa, definida por Kennedy através de Ordem Executiva em 1961. Os programas de ação afirmativa, os quais envolviam apenas os contratantes com o governo e a indústria privada em um primeiro momento, espalharam-se por outras áreas, como universidades e agências governamentais (PERIA, 2004). 
A Universidade da Califórnia foi a pioneira nos Estados Unidos na utilização de programas de cotas (MOEHLECKE, 2004). Segundo a autora, o crescimento na demanda por vagas a partir da década de 1960 levou a universidade a adotar um teste nacional padronizado, além de selecionar os seus ingressantes entre os que figurassem entre os $12,5 \%$ melhores de sua classe no ensino médio. Tais medidas exigiram um contrapeso, que foi a criação das cotas para garantir igualdade nas oportunidades de acesso à universidade (MOEHLECKE, 2004).

\title{
2.2 O sistema de cotas no Brasil
}

O sistema de cotas no Brasil surge de maneira semelhante ao sistema de cotas americano, o que levou muitos a afirmarem que a implementação das políticas públicas de ação afirmativa no Brasil, especialmente as cotas nas universidades, seria uma forma de imitar os americanos, dada a distinção entre as sociedades americana e brasileira (OLIVEN, 2007).

\begin{abstract}
A nação norte americana, desde sua origem, se define constitucionalmente como uma república democrática, avessa às desigualdades de berço tão caras às sociedades aristocráticas da Europa. Ao contrário da nação norte-americana que já nasceu república, o Brasil foi Império a partir da Independência até quase o início do século XX (OLIVEN, 2007, p. 31).
\end{abstract}

As políticas públicas de ações afirmativas no Brasil são construídas após a redemocratização do país, através da exigência de alguns movimentos sociais de uma postura mais ativa por parte poder público a questões como raça, etnia e gênero, bem como a adoção de medidas capazes de solucionar estes problemas, como as ações afirmativas (MOEHLECKE, 2002).

O primeiro registro de ação afirmativa encontrado no país data de 1968, quando técnicos do Ministério do Trabalho e do Tribunal Superior do Trabalho se manifestaram favoráveis à criação de uma lei - que nunca chegou a ser elaborada - que obrigasse as empresas privadas a reservarem uma percentagem mínima para empregados de cor (MOEHLECKE, 2002). 
O movimento negro ressurge no Brasil na década de 1970, realizando passeatas, palestras, debates e diversos trabalhos para conscientizar a sociedade brasileira acerca dos problemas existentes e em busca de um espaço maior para o negro na sociedade (CONTINS; SANT'ANA, 1996). Na década seguinte a Constituição Federal é promulgada, no ano de 1988, representando um importante marco nas mudanças sociais ocorridas no país, tornando crime a prática do racismo e reconhecendo o direito à posse de terra às comunidades quilombolas (LIMA, 2010). Em conjunto com a criação da Fundação Cultural Palmares, tais ações representam uma resposta às reivindicações do movimento negro e uma forma de reconhecimento do valor histórico e cultural dos grupos discriminados (LIMA, 2010).

Nos anos 1990 aparece a primeira proposta de política de cotas, através do Projeto de Lei ${ }^{\circ}$ 783, de 1995, de autoria da então deputada Marta Suplicy (RODRIGUES, 2017). Neste mesmo ano, o qual representa o tricentenário da morte do Zumbi dos Palmares (SILVA SOARES, 2016), acontece a Marcha Zumbi, movimento que representou uma maior aproximação e forma de pressão ao poder público (MOEHLECKE, 2002). Esta pressão se materializa no Programa de Superação do Racismo e da Desigualdade Racial, que apresentava um diagnóstico da prática do racismo e da desigualdade social, reivindicando recomendações de políticas nas áreas de informação, trabalho, educação, saúde, violência, religião, cultura e comunicação (LIMA, 2010).

Fernando Henrique Cardoso, então Presidente da República, recebe o documento no dia 20 de novembro 1995, mesmo dia em que institui o Grupo de Trabalho Interministerial (GTI) para a Valorização da População Negra (MOEHLECKE, 2002; PERIA, 2004). A criação deste GTI se mostrou fundamental para a ampliação da discussão acerca da inclusão do negro na educação, conforme explicita Peria (2004) ao apresentar a proposição ao Ministério da Educação por parte do GTI de medidas que garantissem não apenas o acesso, mas permanência de alunos negros no ensino superior.

As políticas de ação afirmativa ganham destaque na educação no início dos anos 2000 através do sistema de cotas, com a aprovação de duas leis na Assembleia Legislativa do Estado do Rio de Janeiro (ALERJ), que estabeleciam reservas de vagas para a população negra e parda e estudantes oriundos de escola pública na Universidade Estadual do Rio de Janeiro (UERJ) e na Universidade Estadual do Norte 
Fluminense (UENF) (PERIA, 2004). A nível nacional, a Universidade de Brasília (UnB) foi a primeira universidade federal a adotar cotas para negros e índios, em 2004 (BENTO et al., 2016; LIMA; NEVES; SILVA, 2014).

No ano de 2012, o sistema de cotas é regulamentado a nível federal através da Lei $\mathrm{n}^{\circ} 12.711$. Nas palavras de Bento et al. (2016, p.72), a lei é "voltada para estudantes da rede pública em instituições de ensino superior federais, com separação de vagas para candidatos de baixa renda, e autodeclarados pretos, pardos e indígenas". Além dos grupos descritos por Bento et al. (2016), o Artigo $3^{\circ}$ da Lei trata ainda das pessoas com deficiência. A proporção de autodeclarados pretos, pardos e indígenas e pessoas com deficiência será, no mínimo, igual à proporção destes segmentos na população da Unidade da Federação onde está instalada a instituição, de acordo com o último censo da Fundação Instituto Brasileiro de Geografia e Estatística - IBGE (BRASIL, 2012).

A figura a seguir apresenta a divisão proposta pela lei.

Figura 1 - Aplicação da Lei de Cotas.

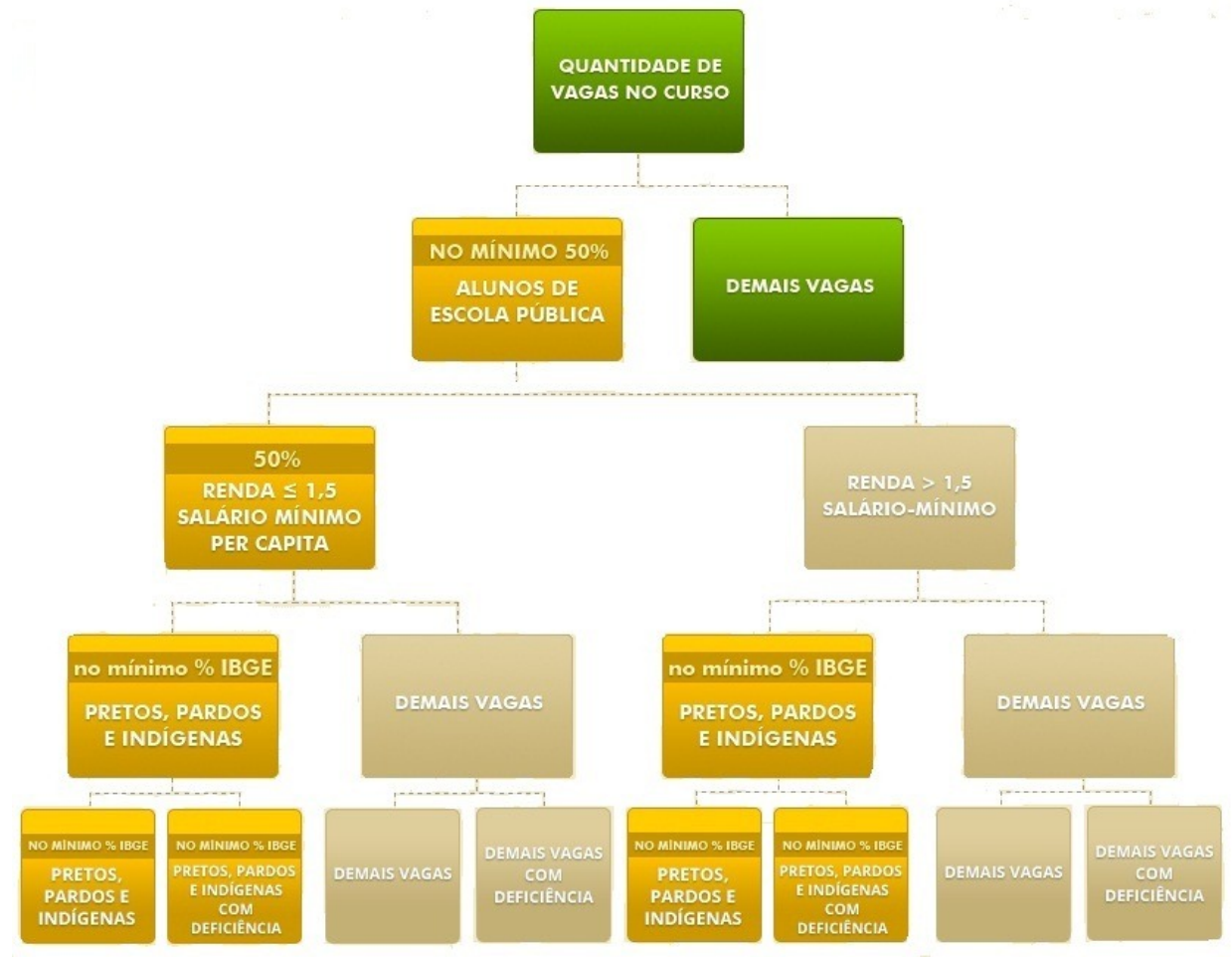

Fonte: Página do MEC na internet ${ }^{3}$. 
Para Marques (2018), a Lei de Cotas representa um avanço significativo, uma vez que busca garantir a igualdade de direitos e minimizar desigualdades raciais na educação superior. O aumento da população negra nas universidades já é apontado em alguns resultados de pesquisas, tornando possível aos negros o fortalecimento do seu pertencimento étnico-racial em um espaço onde a diversidade racial e cultural historicamente não se fazia presente (MARQUES, 2018).

\section{A CRISE DO LIBERALISMO E O SURGIMENTO DO NEOLIBERALISMO}

O neoliberalismo nasce da crise do liberalismo (DARDOT; LAVAL, 2016). Como demonstram os autores, a crise do liberalismo é uma crise da governabilidade liberal, uma vez que apresenta o problema prático da intervenção política em matéria econômica e social. A necessidade da intervenção governamental, advinda dos conflitos de classe que ameaçam a propriedade privada e das mutações organizacionais do capitalismo, põe em crise o liberalismo dogmático (DARDOT; LAVAL, 2016).

Nas palavras de Streeck (2013),

Retrospectivamente, a história da crise do capitalismo tardio desde os anos 70 afigura-se como um desenvolvimento da tensão, muito antiga e fundamental, entre o capitalismo e a democracia - como dissolução progressiva de um casamento forçado, arranjado entre ambos depois da Segunda Guerra Mundial. Ao transformarem-se em problemas de acumulação, os problemas de legitimação do capitalismo democrático perante o capital exigiram como condição para a sua solução que a economia capitalista se libertasse cada vez mais da intervenção democrática (STREECK, 2013, p. 11).

O exposto por Streeck (2013) reforça a explicação de Dardot e Laval (2016), que dissertam que o capitalismo correspondia cada vez menos aos esquemas teóricos das escolas liberais. A lei da oferta e da procura dava lugar a uma oligarquia ligada a políticos que dominava o sistema financeiro, enfraquecendo a mão invisível do mercado. Com o enfraquecimento da mão invisível do mercado, o 
ideal de mercado perfeitamente concorrencial estava cada vez mais distante do capitalismo de grande escala (DARDOT; LAVAL, 2016).

Não obstante tal contexto de crise apresentado, o liberalismo enfrentava ainda uma crise interna entre dois tipos de liberalismo: os reformistas sociais, que defendiam um ideal de bem comum, e os partidários da liberdade individual como fim absoluto (DARDOT; LAVAL, 2016). Nesta dualidade entre o ideal de bem comum e a liberdade individual como fim absoluto, os autores apresentam o spencerismo como uma contraofensiva dos individualistas, que denunciam como traidores e acusam de socialismo os defensores das reformas sociais que visam o bem estar da população. Spencer era defensor do livre mercado, pontuando que a cooperação deveria ocorrer voluntariamente e não de forma coercitiva por intervenção do Estado (DARDOT; LAVAL, 2016).

Spencer traça um paralelo entre a teoria darwiniana da seleção natural e o desenvolvimento econômico, uma vez que acredita na sobrevivência dos mais aptos também a nível econômico e que as disposições legislativas e instituições públicas que estendem as proteções da lei aos mais fracos são ingerências e restrições que atravancam a vida dos cidadãos (DARDOT; LAVAL, 2016).

Tal contexto de crise do liberalismo traz o conceito de neoliberalismo, descrito por Duménil e Lévy (2007) como uma nova fase do capitalismo, com uma dinâmica mais favorável da mudança tecnológica e da rentabilidade, a criação de rendas a favor das classes mais abastadas e a redução das taxas de acumulação. Para Dardot e Laval (2016), o neoliberalismo surge como resposta a uma crise do modo de governo liberal, como forma de superar as dificuldades do capitalismo e dos conflitos sociais. Nesse contexto, surge o sujeito neoliberal, descrito pelos autores como o sujeito competitivo e inteiramente imerso na competição mundial, o qual deve ser empreendedor de si mesmo e responder por seus próprios atos. 


\section{NEOLIBERALISMO DE BAIXO PARA CIMA}

Na América Latina, o Neoliberalismo se tornou um termo que busca se fixar no passado, com desregulação financeira, flexibilização do trabalho, redução de proteções sociais e privatizações (GAGO, 2018). A perspectiva de Gago (2018) de um neoliberalismo enraizado nos territórios e fortalecido nas subjetividades populares, o que a autora chama de neoliberalismo de baixo para cima, pode facilitar a compreensão do atual contexto político brasileiro, representado pela direita. Para Gago (2018), o neoliberalismo de baixo para cima é um modo de considerar a dinâmica que resiste à exploração e à espoliação, que se expande e prolifera através da organização das economias informais.

Um exemplo notável é trazido por Marques (2018), em estudo realizado na Universidade Federal da Grande Dourados. Através de um questionário online, a autora observou que as respostas dos acadêmicos eram carregadas de preconceito e defendiam a meritocracia, além de associarem as políticas de ação afirmativa ao governo de esquerda, ignorando o fato dessas políticas terem início no governo Fernando Henrique Cardoso (MARQUES, 2018).

Tal associação ao governo de esquerda pode ser observada nas respostas ao questionário online: "E se não fosse a Dilma dar as cotas, onde você estaria? Já agradeceu à Dilma hoje?” (MARQUES, 2018, p. 19). A Lei de Cotas é, de fato, publicada durante o governo Dilma, em 2012. Porém, a criação do Grupo de Trabalho Interministerial, instituído por decreto em 1995 pelo então Presidente da República Fernando Henrique Cardoso, possibilitou que este grupo apresentasse proposições ao Ministério da Educação de medidas que garantissem não apenas o acesso, mas a permanência de alunos negros no ensino superior (PERIA, 2004).

A respeito da questão meritocrática, Soares e Baczinski (2018) traçam o ideal da meritocracia como uma ligação direta entra mérito e poder, em que cada indivíduo seria premiado de acordo com as virtudes individuais, independentemente de etnia ou classe social. 
Entretanto, Barbosa (2014) aponta que, no Brasil, a meritocracia está em permanente disputa com o nepotismo, o fisiologismo e os privilégios corporativos. Desta forma, a meritocracia pregada pelo sistema capitalista está distante de ser ideal, sendo apenas mais um meio de dominação ideológica das classes dominantes sobre as classes inferiores (SOARES; BACZINSKI, 2018).

Essa disputa entre a meritocracia e conceitos tão distintos descaracteriza qualquer crítica sobre o sistema de cotas relacionadas às questões meritocráticas. A questão meritocrática do acesso não é renegada pelo sistema de cotas, visto que a concorrência por vagas permanece, embora sob um novo contexto (MOURA; TAMBORIL, 2018).

O fato de os estudantes da Universidade Federal da Grande Dourados empregarem de forma equivocada o conceito de meritocracia caracteriza o enraizamento de ideias neoliberais naquele contexto, reforçando a afirmação de Soares e Baczinski (2018), de que a meritocracia pregada pelo sistema capitalista é apenas mais um meio de dominação.

A adoção de discursos meritocráticos está diretamente relacionada com o padrão de conhecimento eurocêntrico, conforme apontam Auad e Cordeiro (2018).

O padrão de conhecimento construído é, ainda hoje, predominantemente eurocêntrico, sexista e heteronormativo, legitimando uma sociedade historicamente elitizada e meritocrática, o que vai de encontro às políticas afirmativas (AUAD; CORDEIRO, 2018, p. 203).

O padrão de conhecimento construído destacado por Auad e Cordeiro (2018) exemplifica o que Gago (2018) chama de neoliberalismo de cima para baixo, uma vez que, ao legitimar a sociedade meritocrática, estabelece o modelo eurocêntrico como padrão a ser seguido. Para Gago (2018), o neoliberalismo de cima para baixo sinaliza uma modificação do regime de acumulação global, com novas estratégias de corporações, agências e governos, o que leva a uma mutação nas instituições estatais nacionais. 
Enquanto tal concepção é construída de forma institucional, o neoliberalismo de baixo para cima é construído através do enraizamento de ideias neoliberais nos territórios, assentamentos e bairros periféricos, como observado pela autora em seu estudo sobre a Argentina. A penetração financeira nesses bairros e assentamentos é produzida numa paisagem pós-industrial, marcada pelo consumo plebeu, sustentado por uma multiplicidade de fontes de renda, como subsídios do governo, biscates e trabalhos informais (GAGO, 2018). Tais condições, segundo a autora, favorecem o enraizamento de ideias neoliberais nestes territórios.

No Brasil, Fernando Holiday, coordenador nacional do Movimento Brasil Livre (MESSENBERG, 2017), pode ser considerado um exemplo de neoliberalismo de baixo para cima.

Fernando Silva Bispo (Fernando Holiday) nasceu em 1996, na cidade de São Paulo, e apresenta-se em sua página no Facebook como coordenador Nacional do Movimento Brasil Livre e vereador eleito pela cidade de São Paulo, com 48.055 votos. Ostentava, na rede, em outubro de 2016, mais de 171 mil curtidas. Foi aprovado para o curso de filosofia da Universidade Federal de São Paulo (Unifesp), mas não chegou a cursá-lo (MESSENBERG, 2017, p. 628).

Messenberg (2017) destaca que, embora Fernando Holiday seja negro, pobre e homossexual, ele se diz alheio à vitimização, associando-a ao governo de esquerda e afirmando que tal vitimização ganha forma com as cotas raciais e acabam por reforçar o racismo.

Messenberg (2017) aponta o ataque ao Estado por parte de Fernando Holiday, que discursa que o Estado apenas atrapalha a vida do cidadão, representando pedras ou buracos na vida do indivíduo. Tal discurso desconsidera o fato de a razão econômica não substituir a razão do Estado, mas atribuir-lhe um novo papel (GAGO, 2018). 
Em períodos de crise do capitalismo, como a enfrentada no início dos anos 2000 na Argentina, o Estado se mostra importante para a recuperação da economia. Após cinco anos consecutivos de queda do PIB neste período, houve um aumento da renda das classes médias, aumento de emprego e políticas redistributivas (GAGO, 2018). Tais políticas deram maior poder de consumo às classes mais baixas, através de subsídios, representando maior participação do Estado (GAGO, 2018). De acordo com a autora, essa financeirização de cima para baixo através de certos organismos estatais estimulou o consumismo, dando sobrevida ao capitalismo.

Sérgio Camargo pode ser considerado outro exemplo de neoliberalismo de baixo para cima. Nomeado para a presidência da Fundação Palmares, teve sua nomeação suspensa pelo juiz Emanuel José da Silva Guerra, da $18^{\mathrm{a}}$ Vara Federal do Ceará, provavelmente impulsionado pela repercussão negativa por parte da sociedade e da mídia em virtude de suas declarações polêmicas, negando o racismo no Brasil (MINELLA et al., 2020). Cumpre destacar que, posteriormente, o STJ permitiu a nomeação de Sérgio Camargo ao cargo.

Tais manifestações surgiram do movimento Bolsonarista, e Messenberg (2017) exemplifica tais movimentos, com o já mencionado Movimento Brasil Livre, o movimento Vem Pra Rua Brasil e o movimento Revoltados Online, que exibe em suas postagens no Facebook como um ícone o presidente Jair Bolsonaro, o qual é chamado de "Bolsomito". A autora destaca a regularidade de formas e conteúdo de tais movimentos, considerados formadores de opinião, que indicam uma produção discursiva claramente padronizada. "Suspeita-se que a unidade desses conteúdos venha a ser obra da atuação massiva dos Think Tanks de direita no Brasil, nos últimos anos e, em especial, da Atlas Network" (MESSENBERG, 2017, p. 642).

Rigolin e Hayashi (2012) conceituam os Think Tanks. 
Os Think Tanks, como são genericamente chamados os centros de pesquisa, produção e articulação do conhecimento, exercem diversas funções. A mais conhecida é pautar o debate político por meio da publicação de estudos, artigos de opinião e da participação de seus membros na mídia. A mistura entre pesquisa e advocacy faz deles a ponte entre conhecimento e poder. Tornaram-se tão prestigiosos nas últimas décadas que praticamente passaram a representar um novo segmento do sistema político, influenciando a tomada de decisões. Trata-se de um espaço privilegiado de fazer política, que encontra terreno fértil na democracia, em que a disputa pelo poder se dá no campo das ideias (RIGOLIN; HAYASHI, 2012, p. 22).

Se a suspeita de Messenberg (2017) corresponder à verdade, será possível observar também o neoliberalismo de cima para baixo apresentado por Gago (2018), uma vez que os Think Tanks são organizações que se legitimam exercendo o poder soft ${ }^{4}$ (RIGOLIN; HAYASHI, 2012) representam uma estratégia do governo, característica apontada por Gago (2018) deste tipo de neoliberalismo.

Na América Latina, os Think Tanks pró-mercado têm dado uma maior atenção à área da educação nas últimas décadas, intensificando os interesses privados na condução da política educativa, atuando para ampliar sua participação nos processos decisórios e produzir políticas públicas nos países de sua incidência (CAETANO; MENDES, 2020).

De acordo com Caetano e Mendes (2020), os referidos Think Tanks manifestam que o Estado não tem competência para responder aos problemas educacionais. Embora esta afirmativa não esteja presente diretamente no discurso dos acadêmicos do estudo de Marques (2018), a crítica à política de cotas e a associação ao governo de esquerda demonstram um claro direcionamento ao Estado, possivelmente relacionado à atuação dos Think Tanks da direita brasileira. 


\section{CONSIDERAÇÕES FINAIS}

Este trabalho teve por objetivo relacionar as práticas discursivas contrárias à aplicação de políticas públicas de cotas e o conceito de neoliberalismo de baixo para cima, exposto por Gago (2018). Os trabalhos de Marques (2018) e de Messenberg (2017) são exemplos concretos do enraizamento de ideias neoliberais fortalecido nas subjetividades populares.

Os discursos dos universitários apresentados no estudo de Marques (2018) expõem o enraizamento e difusão de ideias neoliberais naquele contexto. A ideia de que as cotas ferem a meritocracia se mostra enraizada naquela comunidade. As frases "E se não fosse a Dilma dar as cotas, onde você estaria? Já agradeceu à Dilma hoje?” (MARQUES, 2018, p. 19) fortalecem o argumento de Oliven (2007) de que o brasileiro é condicionado a ser mais seduzido por valores elitistas.

Entretanto, a questão meritocrática do acesso não é renegada pelo sistema de cotas, conforme demonstram Moura e Tamboril (2018). Embora reconheçam que o ensino superior é um lugar de excelência e meritocracia, as autoras apontam que as cotas não acabam com a meritocracia, pois a concorrência por vagas permanece, embora sob um novo contexto (MOURA; TAMBORIL, 2018).

Ademais, o estudo de Soares e Baczinski (2018) aponta que a meritocracia pregada pelo sistema capitalista é apenas mais um meio de dominação ideológica, muito distante da meritocracia ideal. O fato de, no Brasil, a meritocracia competir com conceitos tão distintos como nepotismo, físiologismo e privilégios corporativos, conforme aponta Barbosa (2014), descredibiliza qualquer crítica ao sistema de cotas relacionadas às questões meritocráticas. As cotas representam uma medida reparatória, em função de desigualdades sociais históricas vividas pelos grupos por ela contemplados, que não ferem a concorrência por vagas (MOURA; TAMBORIL, 2018).

Questões meritocráticas fazem parte do padrão de conhecimento eurocêntrico (AUAD; CORDEIRO, 2018), o qual exemplifica o que Gago (2018) chama de neoliberalismo de cima para baixo, uma vez que, ao legitimar a sociedade meritocrática, estabelece o modelo eurocêntrico como padrão a ser seguido. 
Assim como o padrão de conhecimento eurocêntrico, a atuação dos Think Tanks também pode ser considerada uma forma de neoliberalismo de cima para baixo, uma vez que representa uma estratégia de governo e forma de influenciar a tomada de decisões.

A padronização das produções discursivas dos movimentos Bolsonaristas, como o Movimento Brasil Livre, Vem Pra Rua Brasil e Revoltados Online, podem ser obra da atuação dos Think Tanks de direita no Brasil (MESSENBERG, 2017). O fato de Fernando Holiday, coordenador nacional do Movimento Brasil Livre e pertencente a uma minoria étnico-racial, se posicionar contra a existência de uma medida reparatória por parte do Estado e defini-la como vitimização demonstra como essas ideias estão, de fato, enraizadas na sociedade.

A manifestação por parte dos Think Tanks pró-mercado de que o Estado não tem competência para responder aos problemas educacionais, conforme apontam Caetano e Mendes (2020), parece confirmar a suspeita de Messenberg (2017) sobre a atuação das Think Tanks da direita brasileira. Isso porque o ataque ao Estado e à política de cotas mostra-se presente nos discursos de Fernando Holiday, líder de um movimento de direita brasileiro, conforme trabalho de Messenberg (2017).

Outrossim, embora não haja um ataque direto ao Estado no discurso dos acadêmicos do estudo de Marques (2018), a crítica à política de cotas e a associação ao governo de esquerda demonstram um claro direcionamento ao Estado, possivelmente relacionado à atuação dos Think Tanks da direita brasileira.

O discurso de Estado mínimo e do livre mercado de Fernando Holiday esbarra no fato de o ideal de mercado perfeitamente concorrencial estar longe da realidade, devido aos oligopólios, monopólios e diversos outros fatores que enfraquecem a mão invisível do mercado (DARDOT; LAVAL, 2016). Como apresenta Gago (2018), a razão econômica não substitui a razão do Estado, mas atribui-lhe um novo papel. Este novo papel é perceptível no contexto argentino do início dos anos 2000, em que o Estado intervém através de subsídios estatais e incentivo ao consumo em massa (GAGO, 2018). 
Durham (2005) destaca uma grande lacuna educacional entre estudantes brancos e negros. A associação desta lacuna educacional com a literatura acerca das ações afirmativas aponta que tal lacuna é caracterizada muito mais pela sub-representação histórica da população negra na universidade do que pela diferença entre alunos cotistas e não-cotistas. $\mathrm{O}$ argumento é ratificado pelo estudo de Wainer e Melguizo (2018), que comparam o desempenho de alunos cotistas e não-cotistas no Exame Nacional de Desempenho de Estudantes (ENADE), de 2012 a 2014, não havendo diferenças práticas entre o conhecimento destes grupos distintos (WAINER; MELGUIZO, 2018).

Considerando que o aumento da população negra nas universidades já é apontado em alguns resultados de pesquisas (MARQUES, 2018), o sistema de cotas pode não ser a solução definitiva para os problemas educacionais brasileiros - o fato de o Artigo $7^{\circ}$ da Lei de Cotas estabelecer um prazo de dez anos para promover a revisão do programa (BRASIL, 2012) já indica que a medida não tinha essa pretensão - mas cumpre o que se propõe, democratizando o acesso ao ensino superior.

\section{REFERÊNCIAS}

ABREU, E. N. DO N. DE; LIMA, P. G. Políticas de ações afirmativas: itinerário histórico e pontuações quanto à realidade brasileira. Laplage em Revista, v. 4, p. 179-196, 2018.

ALMEIDA, F. M. DE S.; RODRIGUES, C. T. Avaliação da política de cotas na Universidade Federal de Viçosa. Planejamento e Políticas Públicas, 2019.

ANDRADE, C. Y. et al. Programa de formação interdisciplinar superior: um novo caminho para a educação superior. Revista Brasileira de Estudos Pedagógicos, v. 93, n. 235, p. 698-719, 2012.

AUAD, D.; CORDEIRO, A. L. A. A interseccionalidade nas políticas de ações afirmativas como medida de democratização da educação superior. EccoS - Revista Científica, n. 45, p. 191-207, 2018.

BARBOSA, L. Meritocracia e sociedade brasileira. Revista de Administração de Empresas, v. 54, n. 1, p. $80-85,2014$.

BAYMA, F. Reflexões sobre a Constitucionalidade das Cotas Raciais em Universidades Públicas no Brasil: Referências internacionais e os desafios pós-julgamento das cotas. Ensaio, v. 20, n. 75, p. 325$346,2012$. 
BENTO, A. A. et al. Políticas de cotas raciais: conceitos e perspectivas. Ensaios Pedagógicos, p. 64-81, 2016.

BRASIL. Lei n. 12711, de 29 de agosto de 2012 - Ingresso nas UFS e IFS, 2012.

CAETANO, M. R.; MENDES, V. DA R. Think tanks , redes e a atuação do empresariado na educação.

Educar em Revista, v. 36, p. 1-17, 2020

CONTINS, M.; SANT'ANA, L. C. O movimento negro e a questão da ação afirmativa. Estudos Feministas, p. 209-220, 1996.

DARDOT, P.; LAVAL, C. A nova razão do mundo: ensaios sobre a sociedade neoliberal. São Paulo: Boitempo editorial, 2016.

DUMÉNIL, G.; LÉVY, D. Neoliberalismo: neo-imperialismo. Economia e Sociedade, v. 16, n. 1, p. 1$19,2007$.

DURHAM, E. R. Inequality in education and quotas for black students in universities. Novos Estudos CEBRAP, v. 1, n. SE, p. 0-0, 2005.

FERES JÚNIOR, J. O combate à discriminação racial nos EUA: estudo histórico comparado da atuação dos três poderes. Sociedade em Estudos, n. 1994, 2007.

GAGO, V. A razão neoliberal: economias barrocas e pragmática popular. São Paulo: Elefante, 2018.

LIMA, M. Desigualdades raciais e políticas públicas. Novos Estudos, 2010.

LIMA, M. E. O.; NEVES, P. S. DA C.; SILVA, P. B. A implantação de cotas na universidade: paternalismo e ameaça à posição dos grupos dominantes. Revista Brasileira de Educação, 2014.

MARQUES, E. P. DE S. O acesso à educação superior e o fortalecimento da identidade negra. Revista Brasileira de Educação, p. 1-23, 2018.

MESSENBERG, D. A direita que saiu do armário: a cosmovisão dos formadores de opinião dos manifestantes de direita brasileiros. Sociedade e Estado, v. 32, p. 573-591, 2017.

MINELLA, L. S. et al. Resisting the pressures of conservatism, despite everything. Revista Estudos Feministas, v. 28, n. 1, p. 1-6, 2020.

MOEHLECKE, S. Ação afirmativa: história e debates no Brasil. Cadernos de Pesquisa, v. 117, n. 117, p. 197-217, 2002. 
MOEHLECKE, S. Ação afirmativa no ensino superior: entre a excelência e a justiça racial. Educação \& Sociedade, v. 25, p. 757-776, 2004.

MOURA, M. R. S. DE; TAMBORIL, M. I. B. “Não é assim de graça!”: Lei de Cotas e o desafio da diferença. Psicologia Escolar e Educacional, v. 22, p. 593-601, 2018.

OLIVEN, A. C. Ações afirmativas, relações raciais e política de cotas nas universidades: Uma comparação entre os Estados Unidos e o Brasil. Educação, 2007.

OPIE, T.; ROBERTS, L. M. Do black lives really matter in the workplace? Restorative justice as a means to reclaim humanity. Equality, Diversity and Inclusion: An International Journal, 2017.

PERIA, M. Ação afirmativa: um estudo sobre a reserva de vagas para negros nas universidades públicas brasileiras. O caso do Estado do Rio de Janeiro. [s.1.] Universidade Federal do Rio de Janeiro, 2004.

RIGOLIN, C. C. D.; HAYASHI, M. C. P. I. Por dentro dos "reservatórios de idéias": uma agenda de pesquisa para os think tanks brasileiros. Liinc em Revista, v. 8, n. 16, p. 20-33, 2012.

RODRIGUES, R. J. P. A evolução da política de cota de gênero na legislação eleitoral e partidária e a sub-representação feminina no parlamento brasileiro. Revista Eletrônica Direito e Política, v. 12, n. 1, p. 1-21, 2017.

SILVA SOARES, I. DA. Caminhos, pegadas e memórias: uma história social do movimento negro brasileiro. Universitas: Relações Internacionais, v. 14, n. 1, 2016.

SOARES, K. DA S.; BACZINSKI, A. V. DE M. A meritocracia na educação escolar brasileira. Temas \& Matizes, v. 12, n. 22, p. 36-50, 2018.

SOUZA, Y. H. DE; SECCHI, L. Extinção de políticas públicas: síntese teórica sobre a fase esquecida do policy cycle. Cadernos Gestão Pública e Cidadania, v. 20, n. 66, p. 75-93, 2015.

STREECK, W. Tempo Comprado: A crise adiada do capitalismo democrático. Coimbra: Actual, 2013.

WAINER, J.; MELGUIZO, T. Inclusion policies in higher education: evaluation of student performance based on the Enade from 2012 to 2014. Educacao e Pesquisa, v. 44, n. 1, p. 1-15, 2018.

\section{Notas de Rodapé}

3. Disponível em: https://portal.mec.gov.br/cotas/sobre-sistema.html Acesso em jan. 2021. 
4. O exercício do poder soft é a habilidade de alcançar objetivos por meio da influência, ao invés da coerção (RIGOLIN; HAYASHI, 2012). 